\title{
The role of the cerebellar cortex in the retention of the conditioned eyeblink response with the stimulation of the dorsolateral pontine nuclei as a conditioned stimulus
}

\author{
CAROL DERSARKISSIAN, CHRISTINE G. LOGAN, and RICHARD F. THOMPSON \\ University of Southern Califormia, Los Angeles, California
}

\begin{abstract}
The present study assessed the effects of lesions of cerebellar cortex on conditioned responses (CRs) using stimulation of the pontine nuclei as a conditioned stimulus (CS). Seven male New Zealand albino rabbits were implanted with stimulating electrodes in and around the dorsolateral pontine nuclei (DLPN). They were then trained to DLPN stimulation-airpuff pairings until they acquired the classically conditioned eyeblink response. Following training, the animals were given a lesion of the paramedian, ansiform, and Larsell's HVI lobule. They were then retrained to DLPN stimulation. These animals relearned in 1-9 days. One animal with damage to the interpositus nucleus (IP) neither reacquired to DLPN stimulation nor learned to a tone conditioned stimulus (CS). Together with previous studies from our laboratory, these results suggest that the cerebellar cortex plays an important, though not essential, role in the retention of classically conditioned eyeblink responses to tone, light, lateral reticular nucleus stimulation or pontine nucleus stimulation. However, rabbits in the present study did require significantly longer to reach a stable level of performance after the lesion than they did before the lesion, suggesting that the cerebellar cortex plays a particularly important role in DLPN-stimulation conditioning.
\end{abstract}

Numerous studies have demonstrated that the cerebellum and its brainstem connections are essential for acquisition and retention of the classically conditioned eyeblink response in the rabbit. Recording, stimulation, lesion, and pharmacological studies provide strong evidence that the cerebellum is the site of neural plasticity (Clark, Zhang, \& Lavond, 1992; Foy, Steinmetz, \& Thompson, 1984; Krupa, Thompson, \& Thompson, 1993; McCormick \& Thompson, 1984b; Nordholm, Thompson, Dersarkissian, \& Thompson, 1993).

Development of a classically conditioned response (CR) requires the anatomical convergence of conditionedstimulus (CS) information and unconditioned-stimulus (US) information (Pavlov, 1927; Rescorla, 1988). For eyeblink conditioning, this convergence may occur in both the cerebellar cortex and the deep nuclei. Studies suggest that the US information is carried from the inferior olive, via the climbing fibers (McCormick, Steinmetz, \& Thompson, 1985; Steinmetz, Lavond, \& Thompson, 1989).

This work was supported by the Howard Hughes Summer Fellowship program, awarded to C.D., and by National Science Foundation Grant IBN9215069, National Institutes of Health Grant AF05142, and a grant from Sankyo to R.F.T. Special thanks to JoAnne Tracy, Robert Clark, and Dragana Ivkovich for all their help throughout this study and during the preparation of the manuscript. Correspondence should be sent to R. F. Thompson, Neurosciences Program, University of Southern California, HNB 133, Los Angeles, CA 90089-2520 (email:thompson@neuro.usc.edu).
A number of studies suggest that mossy-fiber projections from the pontine nuclei are critical for relaying auditory CS information to the cerebellum in classical eyelid conditioning. Various studies employing methods of stimulating, lesioning, and anatomical labeling have focused on the role and projections of the pontine nuclei. Successful eyelid conditioning has been achieved by electrical stimulation of mossy fibers of the dorsolateral pontine nuclei (DLPN), the lateral pontine nuclei (LPN), and the medial pontine nuclei (Steinmetz, Lavond, \& Thompson, 1985; Steinmetz, Rosen, Chapman, Lavond, \& Thompson, 1986; Tracy, Krupa, Thompson, \& Thompson, in preparation). In fact, when rabbits are conditioned with pontine stimulation as the CS, some can be switched to a tone CS and show almost perfect retention (Steinmetz, 1990). In addition, extensive bilateral damage of the DLPN and LPN is effective in selectively abolishing CRs to a tone CS, but not CRs to a light CS (Steinmetz et al., 1987). Lesions of the middle cerebellar peduncle, which conveys mossy fibers from the pons to the cerebellum, abolish the CR to visual, auditory, tactile, and pontine stimulation (Lewis, LoTurco, \& Solomon, 1987). Further, anatomical studies employing anterograde and retrograde labeling have demonstrated projections of the pontine nuclei to the cerebellar cortex and nuclei. Although the generally accepted direct projections from the pontine nuclei to the cerebellar nuclei have been questioned (Brodal, Dietrichs, \& Walberg, 1986; Qvist, 1989), there is, nonetheless, evidence strongly supporting these connections (Shinoda, Sugiuchi, Futami, \& Izawa, 1992; 
(A) Rabbit \# 1

(93-242)

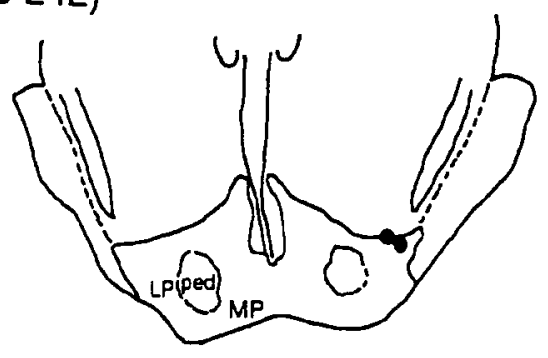

(B) Rabbit \# 2

93-279

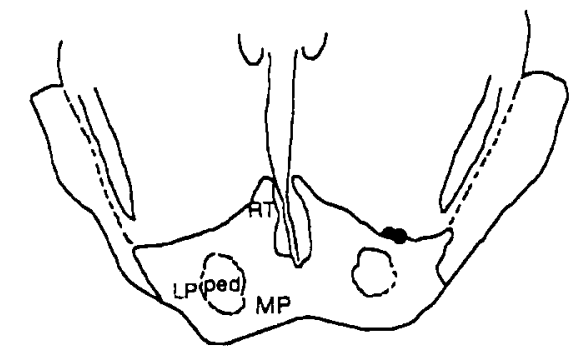

(C) Rabbit \# 3

$$
\text { 93-283 }
$$

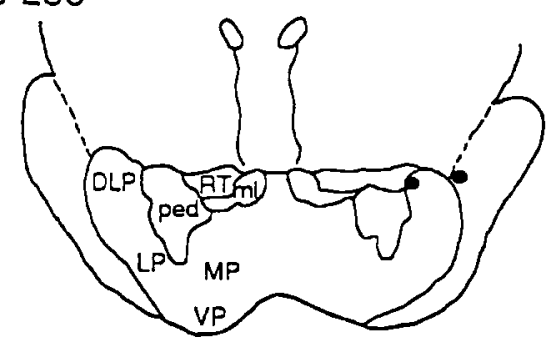

(D) Rabbit \# 4

$$
\text { 93-241 }
$$

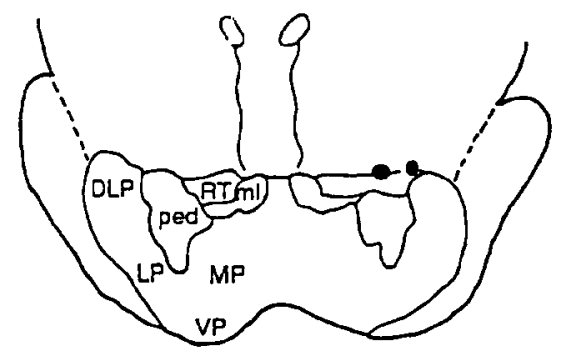

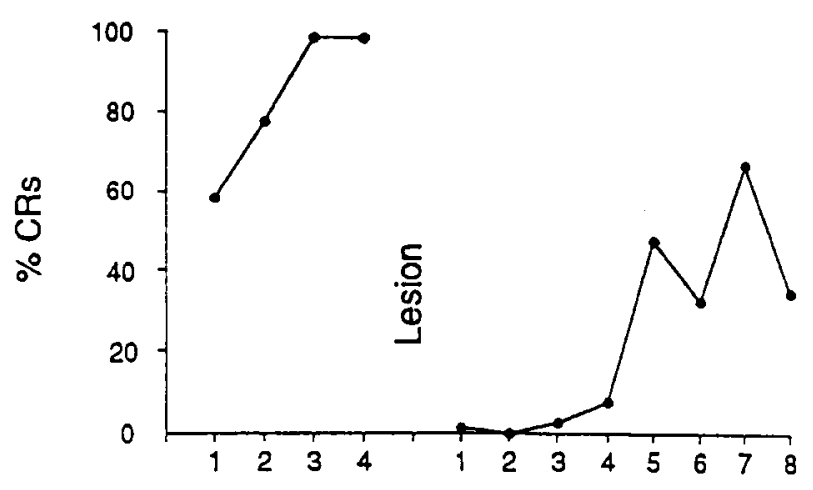
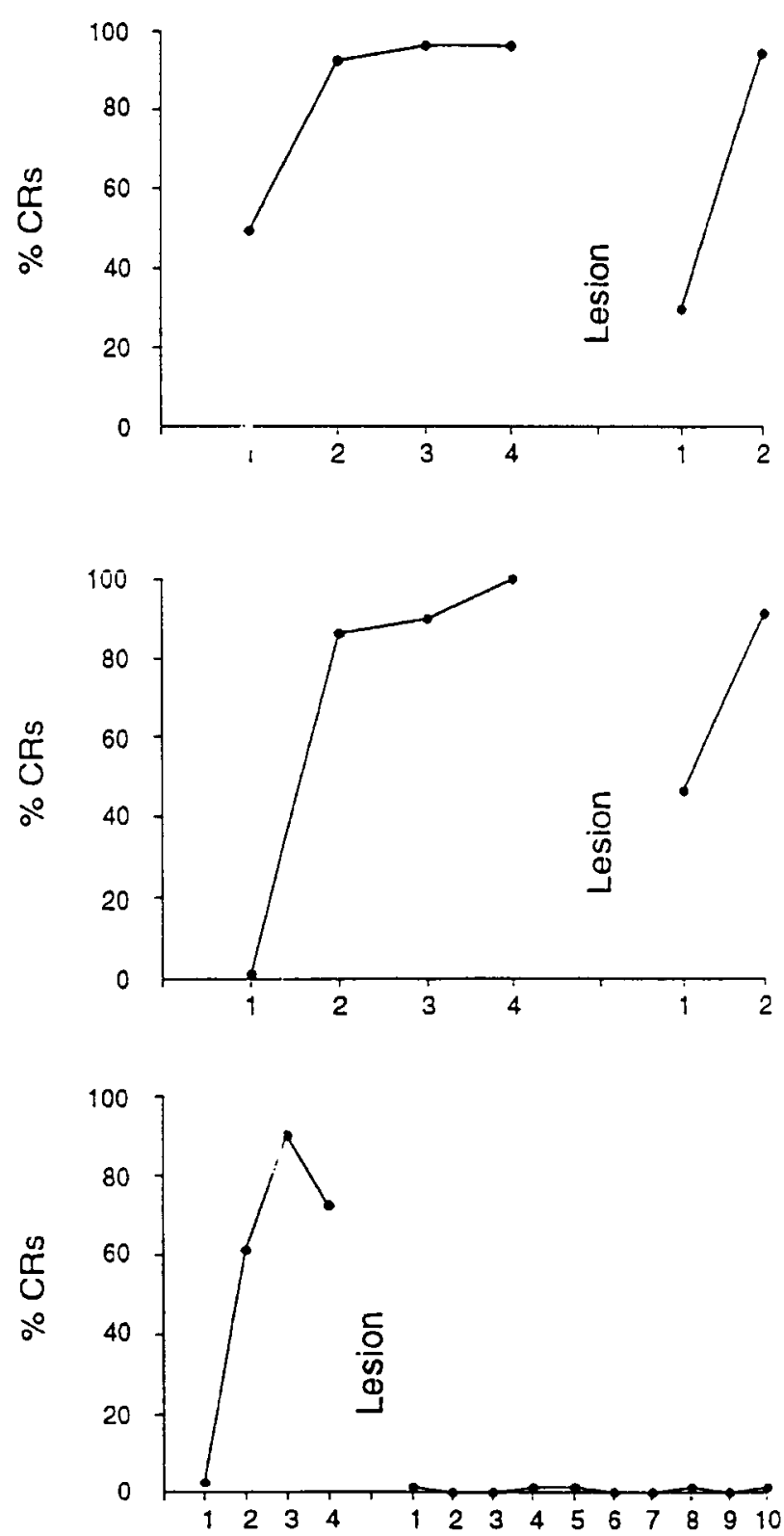

Training Session 
(E) Rabbit \# 5 93-348

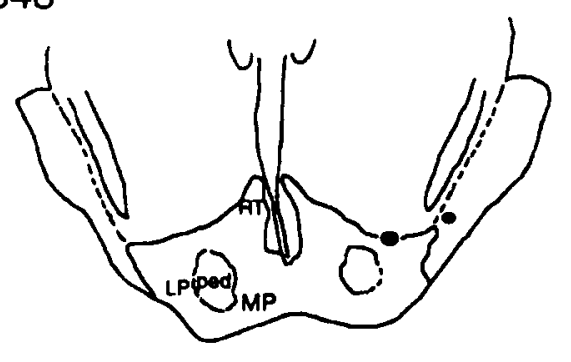

\section{(F) Rabbit \# 6} 93-349

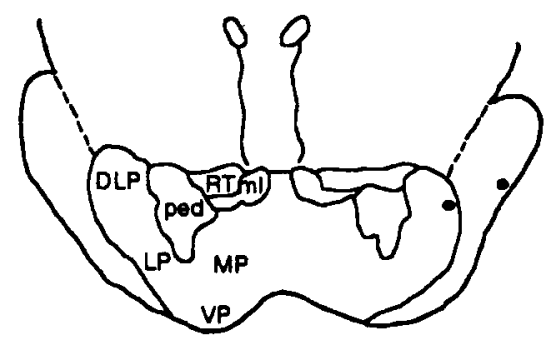

\section{(G) Rabbit \# 7}

\section{3-351}

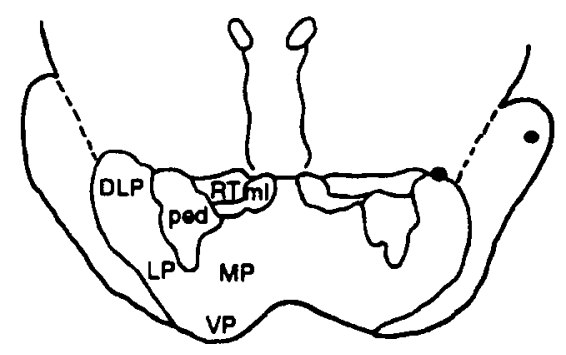

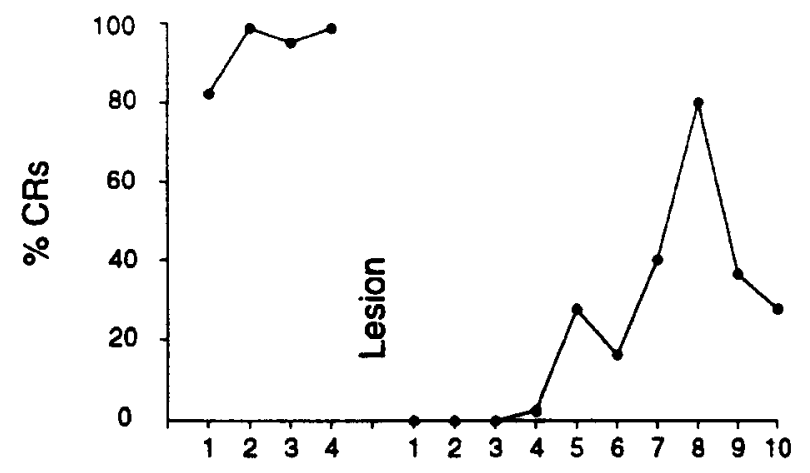
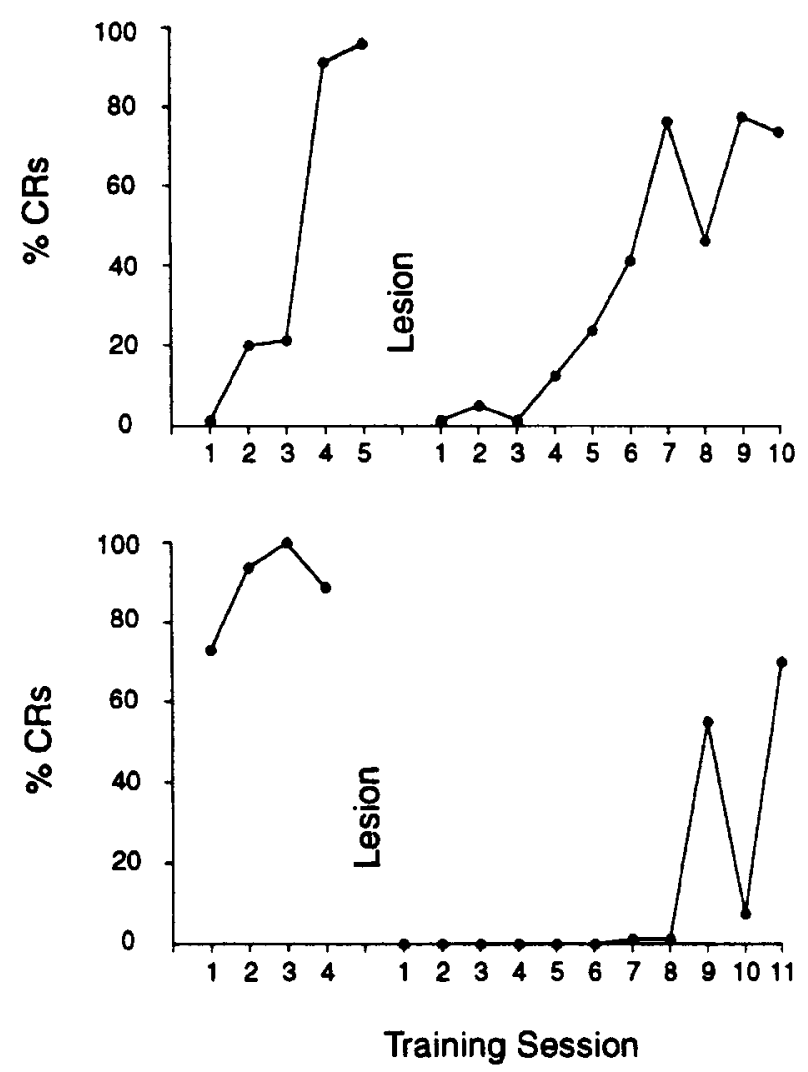

Figure 1. (A) Rabbit 1 profile. (B) Rabbit 2 profile. (C) Rabbit 3 profile. (D) Rabbit 4 profile. (E) Rabbit 5 profile. (F) Rabbit 6 profile. (G) Rabbit 7 profile. Profiles represent effective electrode placement in the pons and acquisition curves of percentage of CRs per day intervals, before and after cortical lesions. DLP, dorsolateral pontine nucleus; LP, lateral pontine nucleus; ml, medial lemniscus; MP, medial pontine nucleus; ped, cerebral peduncle; RT, reticular tegmental nucleus; VP, ventral pontine nucleus.

Steinmetz \& Sengelaub, 1992; Tracy, Krupa, Thompson, \& Thompson, 1995).

This organization of pontine projections to the cerebellum is relevant to the question of the localization of plasticity for the eyeblink conditioning in the cerebellar nuclei or cerebellar cortex. Discrete chemical or electrolytic lesion of the interpositus (IP) nucleus prevented acquisition of eyelid CRs and abolished learned responses in previously trained rabbits when a tone CS was used (Lavond, Hembree, \& Thompson, 1985; McCormick \& Thompson, 1984a; Yeo, Hardiman, \& Glickstein 1985a).
In addition, Yeo, Hardiman, and Glickstein (1985b) reported that lesions of Larsell's hemisphere lobule VI completely abolished tone conditioning. However, Clark and Lavond (1994), Harvey, Welsh, Yeo, and Romano (1993), Lavond and Steinmetz (1989), and Lavond, Steinmetz, Yokaitis, and Thompson (1987) failed to reproduce such results. Direct stimulation of the lateral reticular nucleus (LRN) has also been used as a CS (Knowlton, Lavond, \& Thompson, 1988). Unlike the pontine nuclei, which project to both the cortex and nuclei, the LRN projects primarily to the deep cerebellar nuclei. Lesions of 
cerebellar cortex were ineffective in abolishing CRs to LRN stimulation.

This paper addresses the role of the cerebellar cortex during discrete DLPN stimulation. Animals were trained via pontine stimulation, and large regions of the cerebellar cortex were lesioned. If the DLPN bypass the deep nuclei and project only to the cerebellar cortex, and if the cortex is capable of forming the necessary plasticity associated with the learned eyeblink, subsequent cortical lesions should completely abolish the CR. If however, the DLPN also project to the deep nuclei, and if these connections are sufficient to induce plastic changes, the cortical lesion should not permanently abolish the CR.

\section{METHOD}

\section{Subjects}

Seven male New Zealand albino rabbits were used in the present study. They were housed individually, given free access to food and water, and maintained on a 12:12-h light:dark cycle by the University of Southern California vivarium.

\section{Electrode Implantation}

Surgery was conducted under aseptic conditions. Each rabbit was preanesthetized with injections of xylazine $(8 \mathrm{mg} / \mathrm{kg})$ and ketamine $(60 \mathrm{mg} / \mathrm{kg})$ and then given halothane $(1.5-2 \%)$ during the surgery. Insulated, bipolar electrodes (200- $\mu$ m exposed tips), separated by $1 \mathrm{~mm}$, were implanted in the region of the right DLPN. Electrodes were placed $10.5 \mathrm{~mm}$ caudal, $2.5 \mathrm{~mm}$ lateral, and $20 \mathrm{~mm}$ ventral to bregma in the stereotaxic plane of McBride and Klemm (1968), with bregma $1.5 \mathrm{~mm}$ dorsal to lambda.

\section{Behavioral Training}

Following a 5-7-day recovery period, the rabbits were habituated in a restrainer for $1 \mathrm{~h}$, and the following day, classical conditioning of the left nictitating membrane (NM) response was begun. Conditioning was achieved by pairing a $400-\mathrm{msec}$ train of stimulation (the CS) with a coterminating 100-msec, $2.1 \mathrm{~N} / \mathrm{cm}^{2}(3 \mathrm{psi})$ airpuff. The stimulation range was $10.5-50 \mathrm{~mA}$ (set at $5-10-\mathrm{mA}$ subthreshold for movement of each individual rabbit), in .1-msec pulses through the DLPN at a frequency of $200 \mathrm{~Hz}$. Each rabbit received one session per day consisting of 10 blocks of eight paired (one CS-alone and one US-alone) trials. Movements of the NM were monitored by connecting a minitorque potentiometer to a suture placed in the NM. Delivery of stimuli and recording of NM movements were controlled by a microcomputer. All animals were trained to criterion and overtrained with two additional sessions, to a maximum of five sessions. Criterion for learning was defined by the occurrence of a $5-\mathrm{mm}$ or more NM extension during the CS period, on eight out of nine consecutive trials. Learning was also defined by the occurrence of three consecutive blocks with a performance of $75 \%$ or better (an additional reason for using a $75 \%$ learning criterion was that it gave a better measure of asymptotic response than the eight-out-of-nine criterion during postlesion training).

\section{Cerebellar Aspirations}

After initial training, aspirations were performed on each rabbit. The surgery was done under aseptic conditions. As previously, each rabbit was anesthetized with injections of xylazine $(8 \mathrm{mg} / \mathrm{kg})$ and ketamine $(60 \mathrm{mg} / \mathrm{kg})$ and then given halothane $(1.5 \%-2.0 \%)$ during surgery. For all animals, the paramedian lobule, the ansiform lobule, and the simplex lobule (HVI) ipsilateral to the trained eye were removed by suction by a glass pipette. The cavity was filled with sterile gel foam and then covered with bone wax, and the skin was sutured closed.

\section{Postlesion Testing}

Each rabbit was given a one-week recovery period and then trained to DLPN stimulation as before. Training was given until criterion was met or for 10 successive days. One animal that did not relearn the $\mathrm{CR}$ to stimulation in 10 days was then given 10 days of paired tone-airpuff training.

\section{Histology}

After training, the stimulation sites were marked by passing $100 \mathrm{~mA}$ of direct current for $10 \mathrm{sec}$, and the rabbits were sacrificed with an overdose of sodium pentobarbital. The rabbits were then perfused with saline followed by $10 \%$ formalin. The brains were stored in formalin for a week, embedded in albumin, and sectioned at $80 \mathrm{~mm}$. Brain sections were stained with cresyl violet for cell bodies and Prussian blue for marking lesions.

\section{Data Analysis}

Trials to the eight-out-of-nine criterion and blocks to the $75 \%$ criterion pre- and postlesion were analyzed with paired $t$ tests. Pre- and postlesion CR and unconditioned-response (UR) amplitudes of the first three blocks reaching the $75 \%$ criterion were analyzed with paired $t$ tests. In addition, pre- and postlesion response onset latency and peak CR latency, of the same blocks, were analyzed with paired $t$ tests. A .05 significance level was used in all analyses.

\section{RESULTS}

All animals in this study acquired the conditioned eyeblink response to stimulation of the DLPN. The majority of animals were trained at low levels of stimulation $(M \pm S E=48.5 \pm 21.25 \mathrm{~mA}$, range $=10-150 \mathrm{~mA})$ and acquired fairly rapidly to the eight-out-of-nine criterion $(M \pm S E=100 \pm 44$ trials, range $=20-310$ trials $)$. Further, all animals, with the exception of Rabbit 4 (93241 ), in which the lesion included the IP nucleus, reacquired the CR after cortical lesions $(M \pm S E=434.8 \pm$ 126 trials, range $=69-835$ trials).

Figures $1 \mathrm{a}-1 \mathrm{~g}$ represent the electrode placements and learning curves for each rabbit. All rabbits had electrodes placed in or near the area of the DLPN. Figure 2a summarizes the largest and smallest extent of ansiform, paramedian, and HVI lesions for all animals that reacquired the CR, and Figure $2 \mathrm{~b}$ represents the actual lesions of Rabbit 4 , which did not reacquire postlesion. All animals had fairly complete cortical lesions, and Rabbit 4 had a partial lesion of the IP nucleus of the cerebellum.

Although the difference between pre- and postlesion trials in reaching the learning criterion of eight CRs out of nine consecutive trials did not quite reach significance $[t(5)=-2.529, p=.053]$, there was a significant difference between pre- and postlesion trials in reaching the $75 \%$ criterion $[t(5)=-2.904, p<.035$; Figure 3]. Prelesion conditioning required $12 \pm 4(M \pm S E)$ blocks to reach the $75 \%$ criterion level, while postlesion conditioning required $57 \pm 15$ blocks $(M \pm S E)$.

Response amplitudes on three consecutive blocks of asymptotic responding were compared pre- and postlesion. Although there was considerable reduction in CR amplitude during postlesion training, it did not reach statistical significance $[t(5)=2.11, p=.09$; Figure 4a]. 

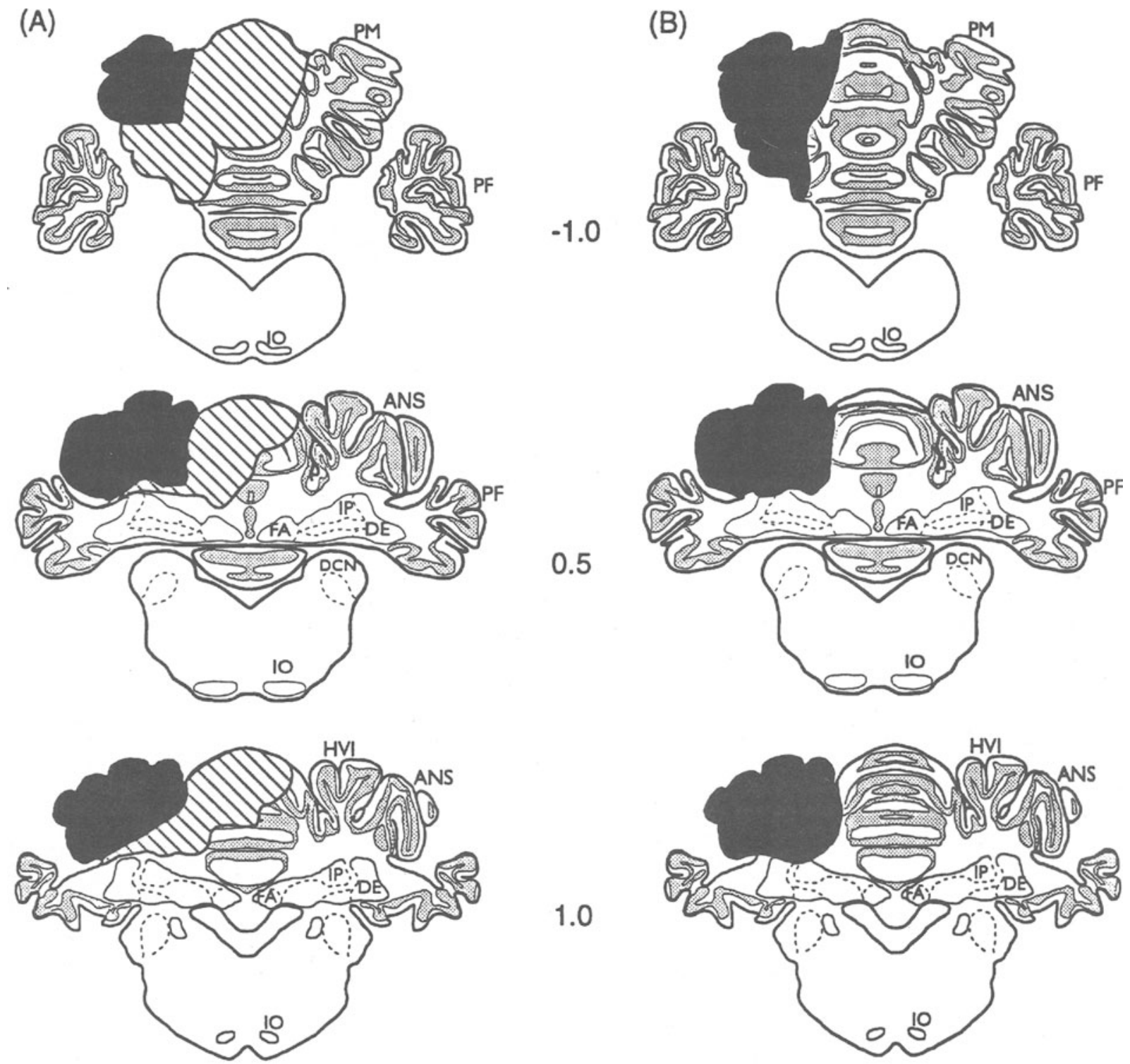

1.0
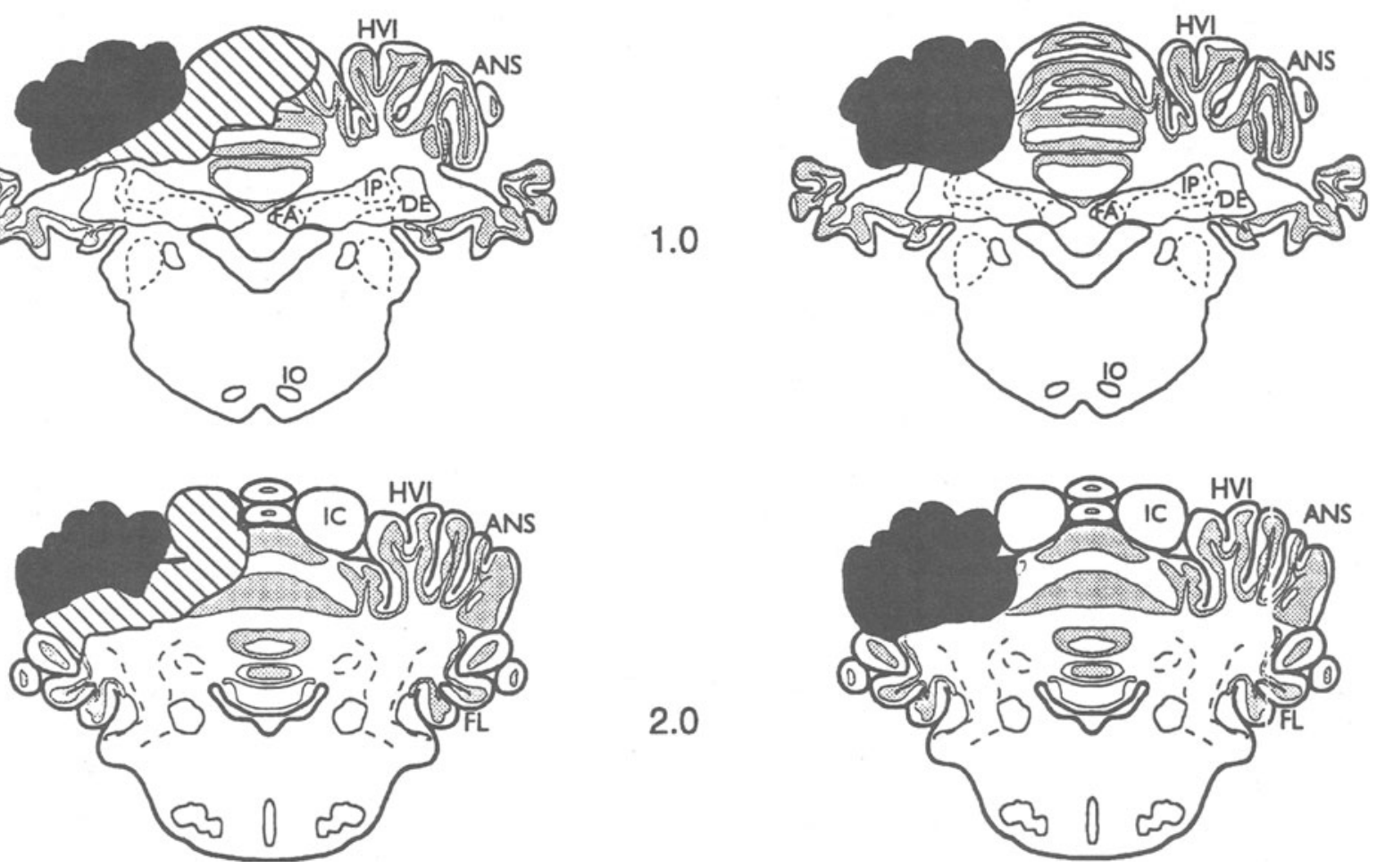

Figure 2. (A) Largest and smallest lesion extents depicted on standard coronal sections. Blackened areas indicate lesions common to all animals. Hatched areas indicate the composite largest extent of lesion found in any animal. (B) Actual lesion of Rabbit 4 on standard coronal sections. Numbers indicate distance from lambda of plane of section in millimeters. ANS, ansiform lobule; DCN, dorsal cochlear nucleus; DE, dentate nucleus; FA, fastigial nucleus; FL, flocculus; HVI, hemispheral lobule VI; IC, inferior colliculi; IP, interpositus nucleus; IO, inferior olive; PF, paraflocculus; PM, paramedian lobule. 


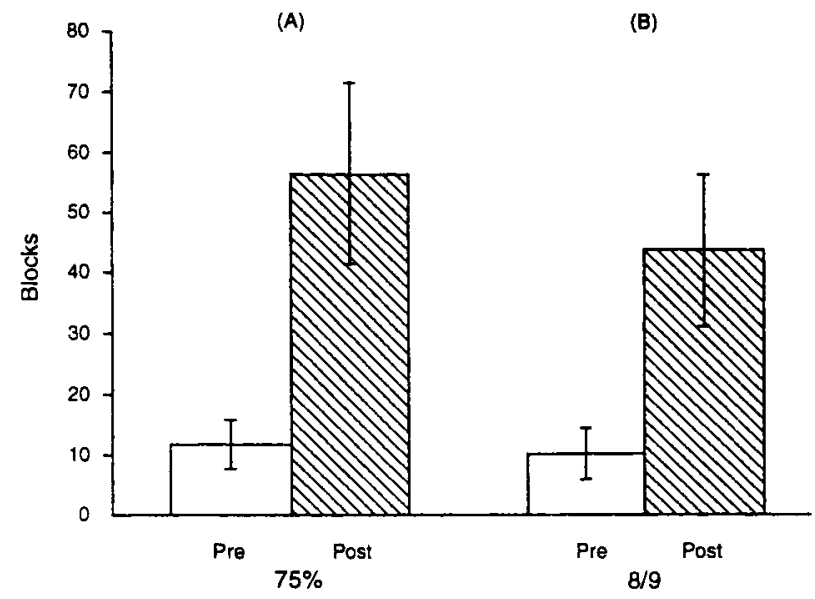

Figure 3. (A) Mean number of blocks to reach the $75 \%$ criterion pre-and postlesion. (B) Mean number of blocks to reach the criterion of eight CRs in nine consecutive trials pre- and postlesion.

There was no significant difference between pre- and postlesion UR amplitudes $[t(5)=-.561$, n.s.; Figure $4 \mathrm{~b}]$.

Further, response onset latency and peak CR latency on the three consecutive blocks mentioned previously were compared pre- and postlesion. There was no significant difference between pre- and postlesion onset latencies $[t(5)=.406, \mathrm{n} . \mathrm{s}$.]. The mean response onset latency was $213 \pm 16 \mathrm{msec}$ prelesion, and $198 \pm 27 \mathrm{msec}$ postlesion. There was no significant difference between pre- and postlesion peak CR latencies $[t(5)=.702, \mathrm{n} . \mathrm{s}$. $]$. The mean peak $C R$ latency was $257 \pm 32 \mathrm{msec}$ prelesion, and $230 \pm 29 \mathrm{msec}$ postlesion.

\section{DISCUSSION}

In the present study, electrical stimulation served as a very effective $C S$ in classical conditioning of the eyelid. Steinmetz et al. (1987) showed that cells within the LPN region are involved in projecting information concerning the occurrence of acoustic conditioned stimuli to the cerebellum. Consistent with this, the majority of animals in the present study learned at a fairly low current and at a rapid pace. This agrees with previous research showing that animals trained with DLPN stimulation learn faster than animals trained with a tone CS (Tracey et al., in preparation).

Aspirations of the paramedian, ansiform, and HVI lobules did not permanently abolish a previously learned, classically conditioned eyelid response. The animals exhibited slight coordination impairment for only about $2 \mathrm{~h}$ postoperatively after recovery from anesthesia. Subsequently, they did not exhibit any nonspecific motor impairments that would have impact on the results. Postlesion animals relearned the CR, although at a delayed pace in comparison with prelesion training to the $75 \%$ criterion level, which was the most consistent response level. Postlesion, the constant asymptotic level of percent response was reduced to $75 \%$, in comparison with a

90\%-95\% level of responding seen prelesion. CR amplitudes were reduced, although the difference was not statistically significant. These findings address the issues of pontine projections to the cerebellar cortex and deep nuclei and the extent to which the cortex functions in the eyelid CR.

Brodal et al. (1986) claim that cat pontocerebellar fibers do not give off collaterals to cerebellar nuclei. Their crystalline WGA-HRP injections into the anterior IP retrogradely labeled only one cell in dorsolateral portion of the pontine nuclei. Shinoda et al. (1992) showed that one-fifth of HRP-stained cat pontine nuclei cells had collaterals to the dentate nucleus (DN), and that the others projected to the cerebellar cortex as mossy fibers without collaterals to the cerebellar nucleus. The axon collaterals in the DN were found in 22 out of 25 pontinenuclei axons that had collaterals to the deep cerebellar nuclei. Further, data conflicting with those of Brodal have been obtained by Steinmetz and Sengelaub (1992) and Tracy et al. (in preparation), by retrograde injection of HRP and fluorescence tracers in the rabbit cerebellum. Projections from the pontine nuclei were found to terminate in the anterior IP nucleus, and the IP was found to send projections to the pontine nuclei. In addition, injections into regions of the cerebellar cortex retrogradely labeled cells in the contralateral pontine nucleus.

Consistent with the evidence of pontine projections to the cerebellar nuclei, specifically to the IP, lesions of the cerebellar cortex do not prevent relearning of CRs. Lavond et al. (1987) showed that New Zealand White rabbits reacquired CRs to an auditory and visual CS after cortical lesions in 1-2 days of retraining. Knowlton et al. (1988) showed that New Zealand White rabbits reacquired CRs to LRN stimulation in 1-3 days. The present study showed that reacquisition of the DLPN CR after cortical lesions can take up to 9 days. In comparison with prelesion conditioning, it took significantly longer

(A)

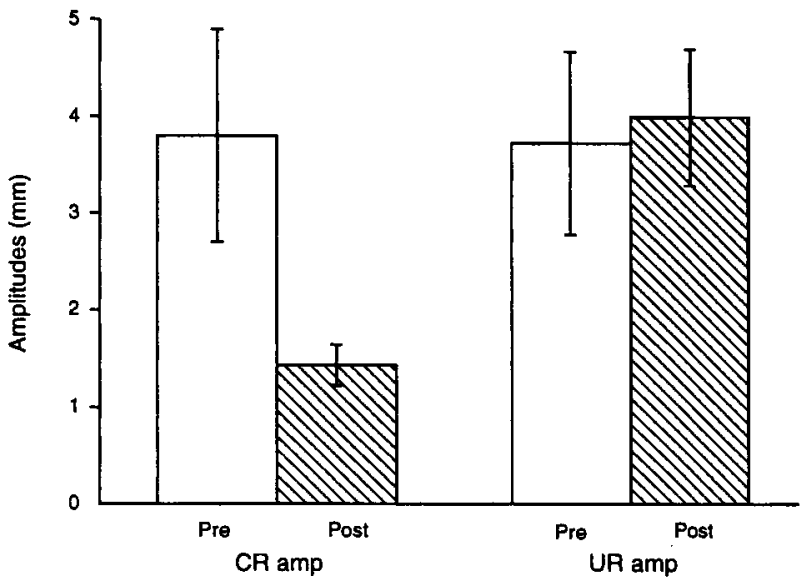

Figure 4. (A) Average CR amplitude in millimeters over three consecutive blocks of asymptotic responding pre-and postlesion. (B) Average UR amplitude in millimeters over three consecutive blocks of asymptotic responding pre- and postlesion. 
to reach the $75 \%$ criterion in postlesion conditioning. In addition, the asymptotic percentage of CRs was not as stable or as high as it was in the prelesion conditioning. Rabbits were shown to reattain preoperative CR levels by the fifth day of retraining (Lavond et al.) and by the sixth day of retraining (Knowlton et al.). As the cerebellar cortex - or at least that part of it that has been removedhas been shown not to be essential for classical conditioning with an auditory, visual, or LRN stimulation CS, it is not essential in conditioning with DLPN stimulation. However, the cortex is critical in terms of the rate and asymptotic level of conditioned learning by DLPN stimulation. This important modulatory role of the cerebellar cortex in eyeblink conditioning was stressed by Lavond et al. (1987) and Thompson (1986), and was recently strongly supported in work by Hesslow (1994).

The idea that the deep nuclei, specifically the IP, are essential for classical conditioning is exemplified in Rabbit 4, which had a lesion of the IP. This animal did not reacquire to the DLPN CS, nor did it acquire to a tone CS after a total of 20 days of training. Lavond et al. (1985) have shown similar results of abolishment of the CR after discrete kainic acid lesions of the dorsal IP nucleus. In addition, Nordholm et al. (1993) showed, via small, discrete reversible lesions of the dorsal IP, that the rabbits were not able to acquire CRs if trained during inactivation. The importance of the IP cannot be overlooked. It has been shown that the firing of many IP neurons correlates with the onset of an acoustic CS and with the performance of the CR (Foy et al., 1984). However, if the IP were solely storing the memory of the CR, it would be expected that the cortically lesioned animals without damage to the IP would retain the CRs postlesion. In this study, the CRs were abolished in most animals, and were relearned postlesion at a delayed rate and with CR performance deficits.

The cerebellar cortex seems more critical when pontine stimulation is used as a CS than when either LRN, visual, or auditory stimulation is used as a CS. This is perhaps due to the fact that the pontine nuclei project a majority of their collaterals to the cerebellar cortex, as shown by Shinoda et al. (1992). The cortex is clearly important in eyelid conditioning, in that without it, CRs to DLPN stimulation are poorer, and learning takes longer. One possible role of the cerebellar cortex in eyelid conditioning may be that of facilitating the operations of the IP nucleus, and thus to accelerate acquisition of the CR and assist in its retention.

\section{REFERENCES}

Brodal, P., Dietrichs, E., \& Walberg, F. (1986). Do pontocerebellar mossy fibers give off collaterals to the cerebellar nuclei? An experimental study in the cat with implantation of crystalline HRP-WGA. Neuroscience Research, 4, 12-24.

Clark, R. E., \& Lavond, D. G. (1994). Reacquisition of eyeblink classical conditioning following large cerebellar cortical lesions in Dutch belted rabbits. Behavioural Brain Research, 61, 101-106.

Clark, R. E., Zhang, A. A., \& Lavond, D. G. (1992). Reversible lesions of the cerebellar interpositus nucleus during acquisition and retention of a classically conditioned behavior. Behavioral Neuroscience, 106, 879-888.

Foy, M. R., Steinmetz, J. E., \& Thompson, R. F. (1984). Single unit analysis of the cerebellum during classically conditioned eyelid responses. Neuroscience Abstracts, 10, 122.

Harvey, J. A., Welsh, J. P., Yeo, C. H., \& Romano, A. G. (1993). Recoverable and nonrecoverable deficits in conditioned responses after cerebellar cortical lesions. Journal of Neuroscience, 13, 1624-1635. HessLow, G. (1994). Inhibition of classically conditioned eyeblink responses by stimulation of the cerebellar cortex in the decerebrate cat. Journal of Physiology, 476, 245-256.

Knowlton, B. J., Lavond, D. G., \& Thompson, R. F. (1988). The effect of lesions of cerebellar cortex on retention of the classically conditioned eyeblink response when stimulation of the lateral reticular nucleus is used as the conditioned stimulus. Behavioral \& Neural Biology, 49, 293-301.

KrUPA, D. J., Thompson, J. K., \& Thompson, R. F. (1993). Localization of memory traces in the mammalian brain. Science, 260, 989991.

Lavond, D. G., Hembree, T. L., \& Thompson, R. F. (1985). Effect of kainic acid lesions of the cerebellar interpositus nucleus on eyelid conditioning in the rabbit. Brain Research, 326, 179-182.

Lavond, D. G., \& Steinmetz, J. E. (1989). Acquisition of classical conditioning without cerebellar cortex. Behavioural Brain Research, 33, 113-164.

Lavond, D. G., Steinmetz, J. E., Yokatis, M. H., \& Thompson, R. F. (1987). Reacquisition of classical conditioning after removal of cerebellar cortex. Experimental Brain Research, 67, 569-593.

LewIS, J. L., LoTurCo, J. J., \& Solomon, P. R. (1987). Lesions of the middle cerebellar peduncle disrupt acquisition and retention of the rabbit's classically conditioned nictitating membrane response. $B e-$ havioral Neuroscience, 101, 151-157.

MCBRIDE, R. L., \& KLEMM, W. R. (1968). Stereotaxic atlas of rabbit brain, based on the rapid method of photography of frozen, unstained sections. Communications in Behavioral Biology: Part A, 2, 179-215.

McCormick, D. A., Steinmetz, J. E., \& Thompson, R. F. (1985). Lesions of the inferior olivary complex cause extinction of the classically conditioned eyelid response. Brain Research, 359, 120-130.

McCormick, D. A., \& Thompson, R. F. (1984a). Cerebellum: Essential involvement in the classically conditioned eyelid response. Science, 223, 296-298.

MCCORMICK, D. A., \& THOMPson, R. F. (1984b). Neuronal responses of the rabbit cerebellum during acquisition and performance of a classically conditioned nictitating membrane eyelid response. Journal of Neuroscience, 4, 2811-2822.

Nordholm, A. F., Thompson, J. K., Dersarkissian, C., \& Thompson, R. F. (1993). Lidocaine infusion in a critical region of cerebellum completely prevents learning of the conditioned eyeblink response. Behavioral Neuroscience, 107, 882-886.

Pavlov, J. P. (1927). Conditioned reflexes. (G. V. Anrep, Trans.). London: Oxford University Press.

QvisT, H. (1989). Demonstration of axonal branching of fibers from certain cerebellar nuclei to the cerebellar cortex and nuclei: A retrograde fluorescent double-labeling study in cat. Experimental Brain Research, 75, 15-27.

RESCORLA, R. A. (1988). Behavioral studies of Pavlovian conditioning. Annual Review of Neuroscience, 11, 329-352.

Shinoda, Y., Sugiuchi, Y., Futami, T., \& Izawa, R. (1992). Axon collaterals of mossy fibers from the pontine nucleus in the cerebellar dentate nucleus. Journal of Neurophysiology, 67, 547-560.

STEINMETZ, J. E. (1990). Neuronal activity in the rabbit interpositus nucleus during classical NM-conditioning with a pontine-nucleusstimulation CS. Psychological Science, 1, 378-382.

Steinmetz, J. E., Lavond, D. G., \& Thompson, R. F. (1985). Classical conditioning of the rabbit eyelid response with mossy fiber stimulation as the CS. Bulletin of the Psychonomic Society, 23, 245-248.

Steinmetz, J. E., Lavond, D. G., \& Thompson, R. F. (1989). Classical conditioning in rabbits using pontine nucleus stimulation as a conditioned stimulus and inferior olive stimulation as an unconditioned stimulus. Synapse, 3, 225-233. 
Steinmetz, J. E., Logan, C. G., Rosen, D. J., Thompson, J. K., Lavond, D. G., \& Thompson, R. F. (1987). Initial localization of the acoustic conditioned stimulus projection system to the cerebellum essential for classical eyelid conditioning. Proceedings of the $\mathrm{Na}$ tional Academy of Science, 84, 3531-3535.

Steinmetz, J. E., Rosen, D. J., Chapman, P. F., Lavond, D. G., \& THOMPson, R. F. (1986). Classical conditioning of the rabbit eyelid response with a mossy-fiber stimulation CS: I. Pontine nuclei and middle cerebellar peduncle stimulation. Behavioral Neuroscience, 100, 878-887.

Steinmetz, J. E., \& Sengelaub, D. R. (1992). Possible conditioned stimulus pathway for classical eyelid conditioning in rabbits. $B e$ havioral \& Neural Biology, 57, 103-115.

Thompson, R. F. (1986). The neurobiology of learning and memory. Science, 233, $941-947$.
Tracy, J., Krupa, D. J., Thompson, J. K., \& Thompson, R. F. (1995). Evidence of plasticity in the pontocerebellar connections during classical conditioning of the rabbit NM response. Manuscript in preparation.

Yeo, C. H., Hardiman, M. J., \& Glickstein, M. (1985a). Classical conditioning of the nictitating membrane response of the rabbit: I. Lesions of the cerebellar nuclei. Experimental Brain Research, 60 , 87-98.

Yeo, C. H., Hardiman, M. J., \& Glickstein, M. (1985b). Classical conditioning of the nictitating membrane response of the rabbit: II. Lesions of the cerebellar cortex. Experimental Brain Research, 60, 99-113.

(Manuscript received August 19, 1994; revision accepted for publication March 9, 1995.) 